\title{
CORRIGENDA
}

\section{Early human milk feeding is associated with a lower risk of necrotizing enterocolitis in very low birth weight infants}

\section{PM Sisk, CA Lovelady, RG Dillard, KJ Gruber and TM O'Shea}

Journal of Perinatology (2007) 27, 808; doi:10.1038/sj.jp.7211826

Correction to: Journal of Perinatology (2007) 27, 428-433. doi:10.1038/sj.jp.7211758.

Following the publication of this article, it was discovered that the data in Table 1 were misaligned. The data for 'Enteral feed volume before NEC onset ( $\mathrm{ml} / \mathrm{kg} /$ day)' is aligned with 'Surgical NEC' with all the data below also off by one line. Following is the corrected version of Table 1:

Table 1 Infant characteristics by human milk group

Low $H M<50 \%$ of HM in enteral

feed first 14 days of life $\mathrm{N}=46$
High $H M \geqslant 50 \%$ of $H M$ in enteral feed first 14 days of life $\mathrm{N}=156$
$5(3.2 \%)^{\mathrm{a}}$

$24.2 \pm 5.6$

$32.3 \pm 4.1$

$2(1.3 \%)$

$2(1.3 \%)$

$22(14.1 \%)$

$1112.8 \pm 17.8^{\mathrm{a}}$

$28.1 \pm 0.2^{\mathrm{a}}$

$136(87.1 \%)^{\mathrm{a}, \mathrm{b}}$

Gestational age (weeks)

Respiratory distress syndrome

$30(65.2 \%)$

Abbreviations: HM, human milk, NEC, necrotizing enterocolitis.

All continuous data are expressed as mean \pm s.e.m. Categorical data are expressed as number (percentage).

${ }^{\mathrm{a}}$ Unadjusted values significantly different, $P<0.05$.

${ }^{\mathrm{b}} \mathrm{No}$ longer significant when adjusted for gestational age, remained significantly different after controlling for birth weight.

\section{International collaborative research. A Colombian model that promotes infant health and research capacity}

\section{MA Rojas, JM Lozano and MX Rojas}

Journal of Perinatology (2007) 27, 808; doi:10.1038/sj.jp.7211885

Correction to: Journal of Perinatology (2007) 27, 738-743. doi:10.1038/s.jp.7211827

Following the publication of this article, Dr Rojas would like to emphasize the following points:
1. Both Colombian and US partners participated in study design activities.

2. Laura Charry participated as research assistant in the Colombian CPAP trial. 